\title{
Anabases
}

ANABASES Traditions et réceptions de l'Antiquité

13 | 2011

Varia

\section{John RAY, The Rosetta Stone and the Rebirth of Ancient}

Egypt

\section{Ève Gran-Aymerich}

\section{OpenEdition}

\section{Journals}

Édition électronique

URL : http://journals.openedition.org/anabases/2115

DOI : 10.4000/anabases. 2115

ISSN : 2256-9421

\section{Éditeur}

E.R.A.S.M.E.

\section{Édition imprimée}

Date de publication : 1 mars 2011

Pagination : 313-314

ISSN : 1774-4296

\section{Référence électronique}

Ève Gran-Aymerich, «John RAY, The Rosetta Stone and the Rebirth of Ancient Egypt », Anabases [En ligne], 13 | 2011, mis en ligne le 01 novembre 2011, consulté le 22 septembre 2020. URL : http:// journals.openedition.org/anabases/2115; DOI : https://doi.org/10.4000/anabases.2115

Ce document a été généré automatiquement le 22 septembre 2020.

(c) Anabases 


\title{
John RAY, The Rosetta Stone and the Rebirth of Ancient Egypt
}

\author{
Ève Gran-Aymerich
}

\section{RÉFÉRENCE}

John RAY, The Rosetta Stone and the Rebirth of Ancient Egypt, Londres, Profilebooks LTD, 2007, 200 p.

15,99 livres / ISBN 9781861973344.

1 Professeur d'égyptologie à Cambridge University, John Ray se propose dans cet ouvrage destiné au grand public cultivé de rendre compte, à partir de la pierre de Rosette, de la résurrection de l'Égypte, qu'il envisage sous de multiples aspects ; l'objet lui-même non seulement participe, par son texte, de l'histoire d'une science, mais constitue aussi un jalon important dans l'histoire politique et culturelle franco-britannique, et enfin soulève la question très contemporaine et brûlante de sa valeur symbolique et de son appartenance discutée au patrimoine universel ou national égyptien. L'introduction détermine clairement les trois axes principaux développés en neuf chapitres, qui constituent l'esquisse d'une histoire de l'égyptologie en liaison avec l'histoire politique européenne et élargie à une réflexion sur le statut des œuvres d'art et des monuments dans le monde contemporain. Les quatre premiers chapitres rendent compte du contexte de la découverte et du déchiffrement de la pierre, avant et après la campagne d'Égypte de 1798, et évoquent la personnalité et la carrière des deux génies qui s'engagèrent dans le déchiffrement, Thomas Young le Britannique et le Français J.-F. Champollion. Les chapitres 5 à 7 illustrent « the Rebirth of Egypt " par le déchiffrement des hiéroglyphes, dont les principes et les effets sont mis en évidence, et par la présentation de l'œuvre et de la personnalité de Champollion. L'héritage du «Déchiffreur » suscite le rapprochement avec d'autres travaux du même type, sur le linéaire B ou le système de l'écriture maya, et l'évocation de quelques grandes figures de l'égyptologie européenne, la France n'étant représentée que par A. Mariette. Les 
deux derniers chapitres reviennent à la pierre elle-même pour, d'une part, analyser les données historiques contenues dans le texte qu'elle porte et, d'autre part, lui restituer sa place dans l'histoire moderne depuis 1802, date de son entrée au British Museum. Aux rivalités franco-anglaises ont succédé les débats contemporains sur la question de son lieu légitime de rattachement et de conservation, qui donne lieu à une large réflexion appuyée d'exemples variés sur le rapport des nations à leur passé lointain et aux objets et monuments qui en témoignent. Cet ouvrage offre des points de vue originaux et présente l'attrait d'une écriture aisée et alerte.

\section{AUTEURS}

\section{ÈVE GRAN-AYMERICH}

chercheur auprès de l'Académie des inscriptions et belles-lettres aymerich@ens.fr 